\title{
مجلس إدارة المجلة
}

- أ.د ـ أمل محم بيومى مهران عميد الكلية ورئيس مجلس الادارة

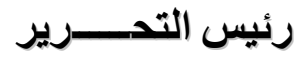

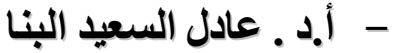

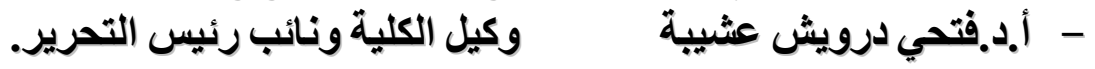
- أ.د. غادة عبد الفتاح غتورى عميد الكلية ورئيس التحرير السابق. - أ.د. - أدادية اندراوس البرنثاوي

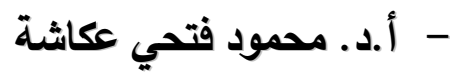
- أ.د. إسماعيل محم دياب - أ. أد. علي عبد العظيم سلام دياب

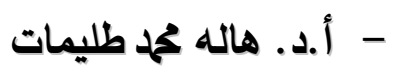

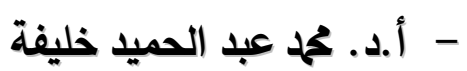

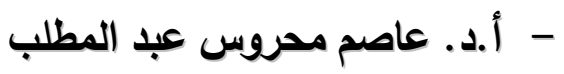
- إ.د.محم إبراهيم أبو خليل

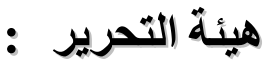

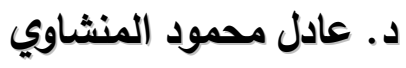

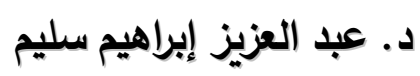

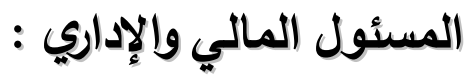

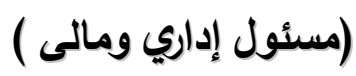

$$
\begin{aligned}
& \text { 1- 1. عصام شوقى غنيم } \\
& \text { سكرتارية المجلة : } \\
& \text { 1- أ. رحاب زكى قناوى } \\
& \text { 2- أ. لمياء فتحي الجندي رهاي }
\end{aligned}
$$




\section{مستشارو التحرير* (مصر)}

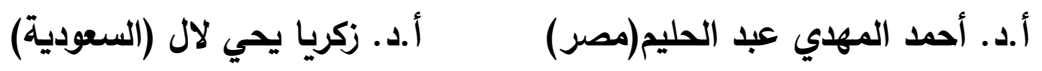
أ. أ. د. زيدان أحمد السرطاوي (السعودية)

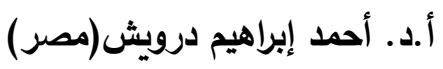

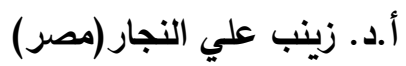
أ.د. أحمد حسن سيف الدين(مصر) إدمبر) أ.د. أ. سام عبدالكريم عمار (سوريا) أ.د. أحمد عبد الجواد حسنين(مصر) أدمد لديف) أ.د. ساميه لطفي الأنصاري(مصر) أد عدار) أ.د. أحمد محمة إبراهيم(مصر) أجراد

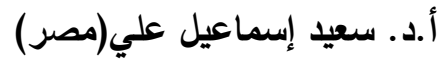

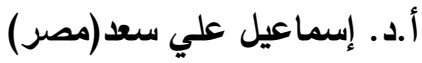

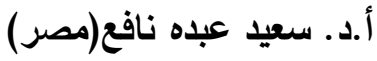
أ.د. إسماعيل احمد صادق(مصر) إلديل أ.د. سيد احمد عثمان(مصر) أد عديد

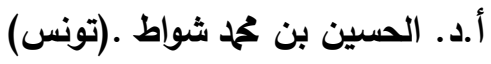
أ.د. سيد محمود الغراب(مصر) أدمان لمدر) أ.د. امال احمد مختار صادق(مصر) الهرين

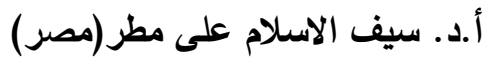
أ.د. آمال عبد السميع باظه (مصر)

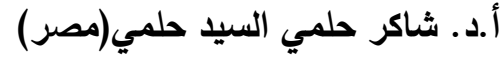
أ.د. بو حفص بالعيد مباركي (الجزائر) أ.د. شبل بدران الغريب(مصر)

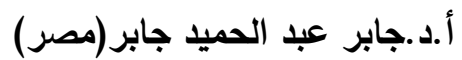
أ.د. صالح عبدالله جاسم (الكويت)

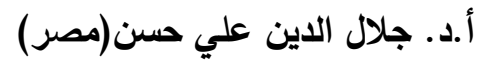
أ.د. صبحي شرف(مصر) أ.د. جمال علي خليل الدهثان(مصر)

أ.د. صبحي عثمان خليل(مصر) أ.د. صلاح الدين عبد السلام الجندي(مصر)

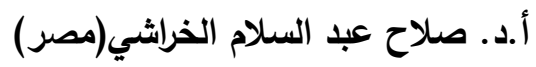
أ.د. طاهر سليمان حمودة(مصر) أ.د. أ.عامر بن عبدالله الثهراني (السعودية) أ.د.عبد الرحمن أحمد الأحمد .(الكويت) الثرائ)

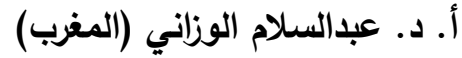
أ.د. عبد العال أبو العلا عبد العال(مصر) العران العزي) أ.د. عبد العال حامد عجوه(مصر) أ. د. أ. عبدالعزيز السرطاوي (الامارات) أ. د. عبدالعزيز عبدالرحمن كمال (قطر) أ.د. جمال محمود حجر(مصر) أ.د. حامد مصطفي عمار (مصر) أ. د. أ. حسن المغيدي (السعودية) أ.د. حسن حسين البيلاوي(مصر) أ.د. حسن عبد العال (مصر) أ.د. حسين محمد سلام الكاشف(مصر) أدمر) أ.د. حلمي احمد الوكيل(مصر) الديل أ.د. خليل يوسف الخليلي (البحرين) أ.د. داود عبدالملك الحدابي (اليمن) أ.د. رضوي مصطفي عاشور(مصر) أد. داود عبدا أ.د. رشدي احمد طعيمة(مصر) 


\section{مستشارو التحرير*}

أ.د. أ. محم سعد الدين عبد الرازق(مصر) أ. أ. د. تحمج سعيد الصباريني (الأردن)

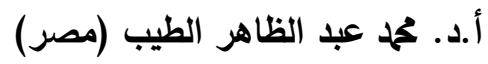

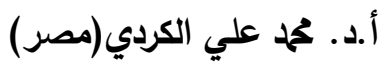
أ. أ. د. محمد عودة الريماوي (الأردن)

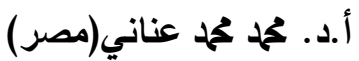

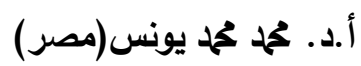
أ.د. أ.دحم نبيل نوفل يونس (مصر)

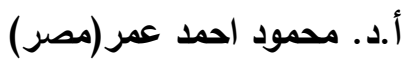
أ.د. محمود عبد الحليم منسي(مصر) أد. مدمود احمر) أ.د. أ. محمود فتحي عكاشة عدور (مصر)

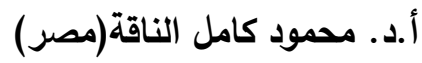
أ.د. مدحت أحمد النمر (مصر) أ.د. مصطفي محما إسماعيل شلبي(مصر) آد الندر) أ.د. ممدوح عبد الله الكناني(مصر) أ.د. منصور أحمد غوني (السعودية) أ. أ.د. ناديه زكي بثاي(مصر) أمدر) أ.د. نبيله إبراهيم إسماعيل (مصر) أ. د. نسيم علي داود (الأردن)

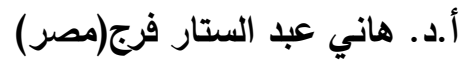
أ.د. هلى حسن الخاجة (البحرين)

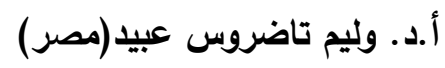
أ.د. هانى عبد الستار فرج (مصر) أ.د. دان ثان دوهورنثيل (فرنسا )
أ. د.عبداللطيف حيدر الحكيمي (اليمن)

أ.د.عبد الله جمعة الكبيسي (قطر). أ. د.عبدالله خضر مدني (السودان) أ.د.عبد المعطي عبد البصير علي(مصر)

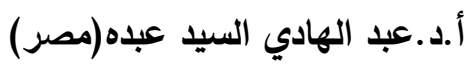
أ.د. عبد العزيز عبد السلام حمودة(مصر) أ. د. عبدالقوي الزبيدي (عمان) أ. أ. د.عدنان الأمين (لبنان)

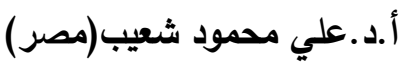

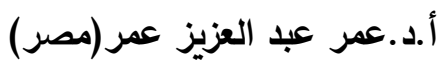

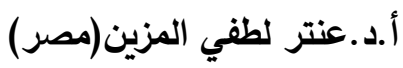

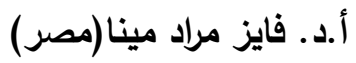
أ.د. فوزي سعد محم عيسي(مصر) أ. د. كايد إبراهيم عبد الحق (الأردن) أ.د. كريمان عويضة منشار نجم(مصر) أ. أ. د. كمال مرسي (الكويت) أ.د. كمال نجيب الجندي(مصر)

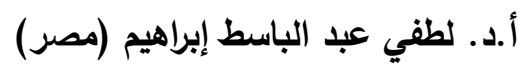
أ.د.ماجدة إبراهيم الباوي (العراق)

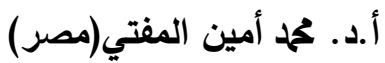

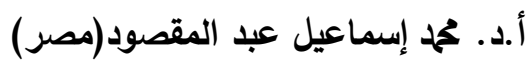

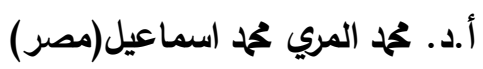
أ.د. محمد الثيخ حمود .(سوريا) أ.د.محمد بن شحات الخطيب (السعودية) أ.د. ا.د. جهاد حمدان · (الأردن ) 


\section{كلمة العدد}

أ.د / أمل عحم بيومى مهان

عميد الكلية ورئيس هيئة تحرير المجلة

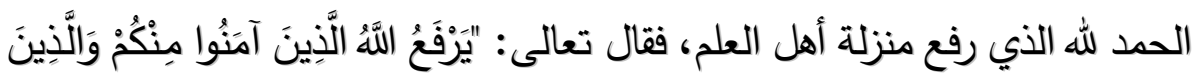

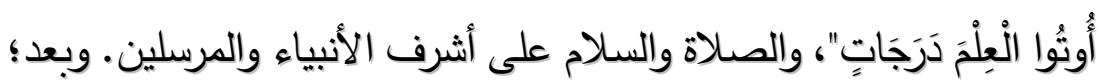

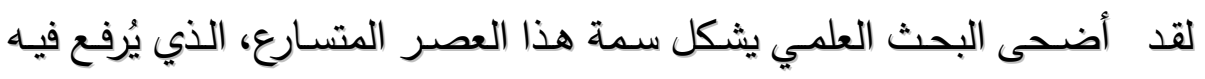

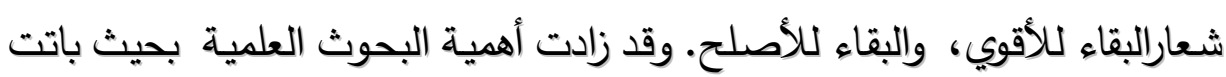

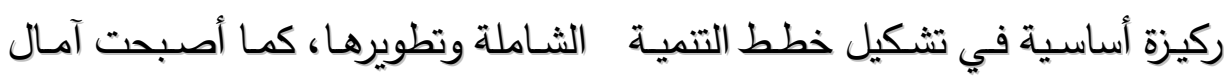
المجتمع في الرقي والتقدم في شتي القطاعات معلقة على البحث العلمي فيما يقدمه

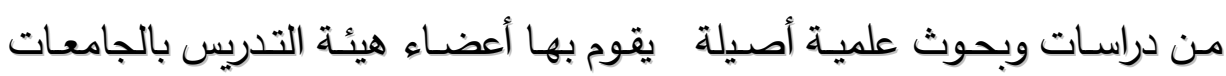
والباحثون والمهنيون. ولايختلف اثنان في أهمية البحث العلمي لفتح مجالات الإبداع والفن والتميز لدى الأفراد والشعوب في المجتمعات مهما تعددت واختلفت ثقافاتها.

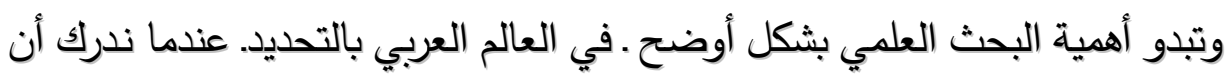

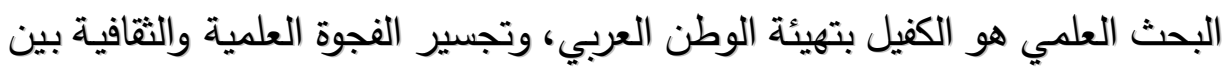
العالم العربي والعالم المتقدم، والإسهام في تحسين المناخات الإنسانية في عالمنا العربي.

وانطلاقاً من إحدى وظائف التعليم العالى ومؤسساته المختلفة المتمثلة في الاهتمام

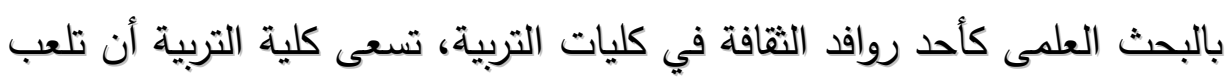

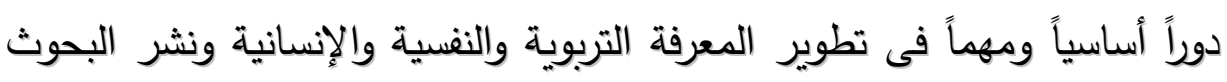
المتصلة بتلك المجالات، وإنطلاقا من هذا الدور تبادر كلية التربية -جامعة دمنهور إلى تقديم العدد (الثالث) فى مجلدها الثانى عشر من مجلتها: (مجلة الدراسات التربوية والإنسانية) الذي يعتبر استمراراً لمسيرة المجلة، في إثراء العلمية

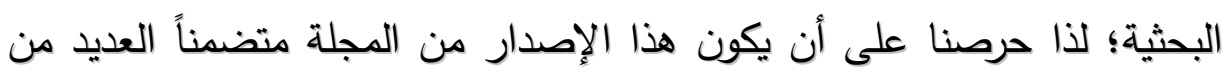
الموضوعات البحثية الحديثة في مجال البحث التربوى لذلك تم التئ التقاء الأبحاث 
بعناية لتحقق الفائدة المرجوه، وهذه البحوث هي: البحث الأول بعنوان فعالية برنامج تدريبي قائم على التدريس المصغر باستخدام الفيديو بالهاتف المحمول في تنمية المهارات التدريسية لاى الطلبة المعلمين بكلية التربية الأساسية بدولة الكويت." واستهدف البحث الوقوف على فاعلية برنامج تدريبي مقترح قائم على استراتيجية التدريس المصغر باستخدام تطبيق

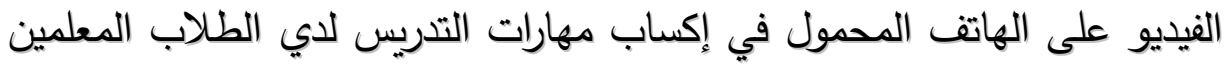
في كلية التربية الأساسية بدولة الكويت.، وجاء البحث الثانى بعنوان" العدالة التهابئ التظظيمية المدركة وعلاقتها بالثقة التنظيمية لاى أعضاء هيئة التدريس في كلية التربية بنين جامعة الأزهر بالقاهرة ... دراسة ميدانية"' واستهدف البحث التعرف على مستويات كل من العدالة التنظيمية، والثقة التتظيمية كما يدركها أعضاء هيئة التدريس في كلية التربية بنين جامعة الأزهر بالقاهرة، ودلالة الفروق في مستويات كلٍ منهما تبعاً لمتغيري (الدرجة العلمية والتخصص "القسم العلمي")، وكذلك الكثف عن واقع العلاقة بين مستوى العدالة

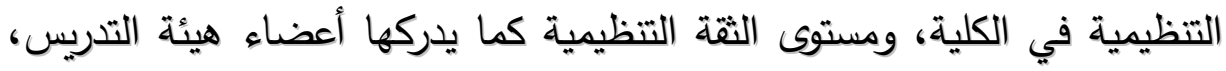
بينما جاء البحث الثالث بعنوان: " العمالة الوافدة في دول الكويت " تهدف الدراسة الحالية الى تحرك الجهات المسؤولة حول قضية ارتفاع اعداد العمالة الوافدة بشكل ملحوظ ودراسة اسباب تلك الظاهرة ووضع الخطط والحلول المناسبة لحل تلك المشكلة مع تفعيل دور المواطنين في تلك القضية، والبحث في امكانية الاعتماد على العمالة الوطنية اثثاء وضع خطط مستقبلية عند الاستغناء الجزئي عن العمالة الوافدة التي انطلقت خلال جائحة كورونا من قرارات حكومية، بالإضافة تحليل اراء

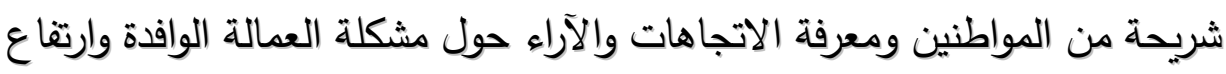
اعدادها والقدرة على الاحلال بالإضافة عن امكانية الحكومة لإعادة التركيبة 
أما البحث الرابع فقد حمل عنوان: " فعاليـة برنـامج تدريبي قائم على إنى

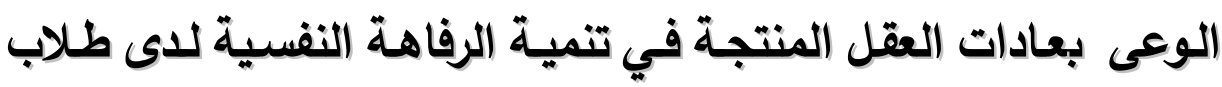

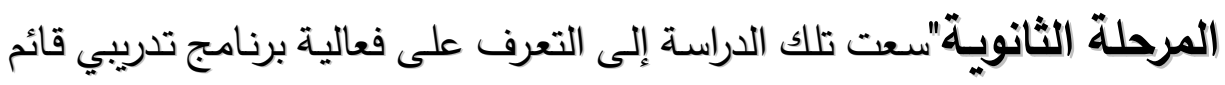
على الوعى بعادات العقل المنتجة في تتمية الرفاهة النفسية لاى طلاب المرحلة

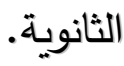

وجاء البحث الخامس بعنوان " فعاليـة التـدربب على استراتيجيات التعلم

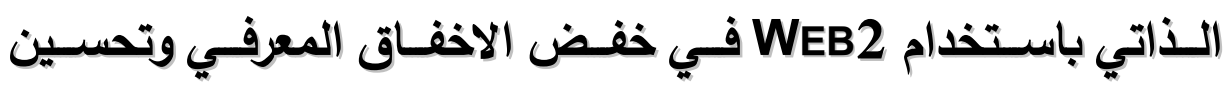
الاندماج والأداء الأكاديمي لاى طلاب الجامعة المتعثرين دراسياً" لايهدف

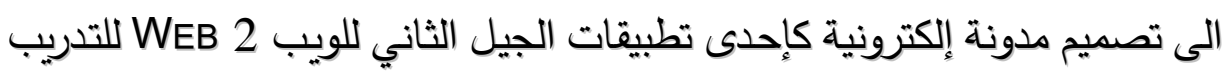
علي بعض استراتيجيات التعلم الذاتي للطلاب المتعثرين دراسياً بكلية التربية بجامعة التيات كفر الثيخ من خلال محتوى دراسي لمقرر سيكولوجية التعلم .

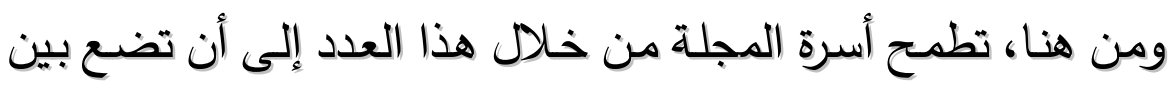

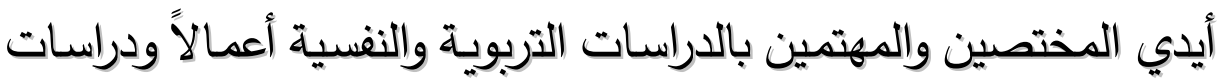
تري أنها ستسهر من خلال ما تتمتع به من رصانة وعمق ومنهجية، في

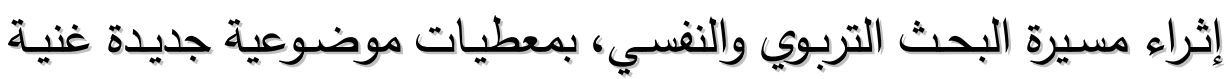
ومفيدة.

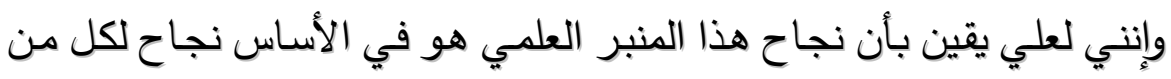
يسهم في تقديم هذه الجهود العلمية المتميزة في مجالات التربية وعلم النفس واعتبارا

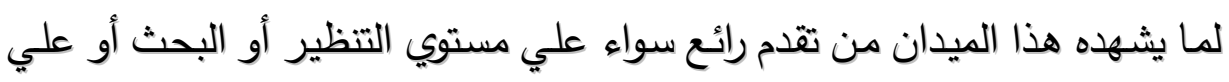
مستوي تطور فنياته وأساليبه، وتتوع مجالات استخدامه.

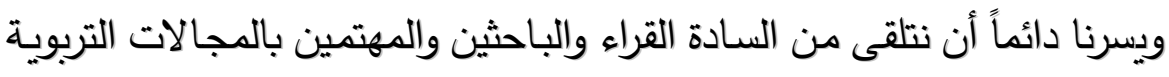
والعلوم الإنسانية مقترحاتهم وآرائهم لتحقيق المزيد من التطور لنستكمل معاً الرسالة الترائ

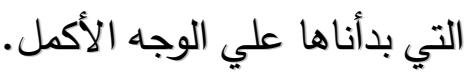


2020 - مجلة الدراسات التربوية والانسانية . كلية التربية ـ جامعة دمنهود ـ المجلد الثانى عشر - العدد الثالث

وفي النهايـة أشكر جميع الزملاء في أسرة المجلة على مـا يبذلونه من جهود

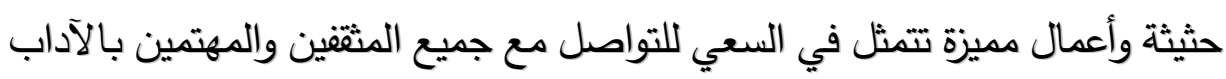

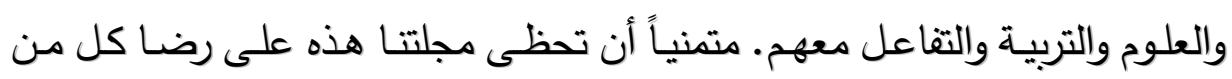

القارئ والباحث والناقد وأن تكون متميزة ومميزة.

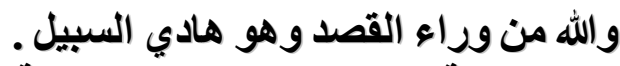

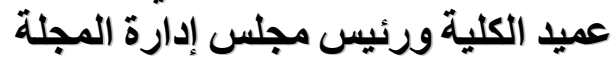

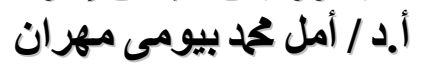




\section{مجلة كلية التربية - جامعة دمنهور}

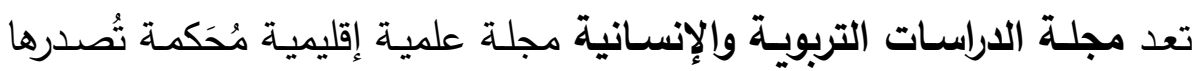

كليـة التربيـة - جامعـة دمنهور بجمهوريـة مصر العربيـة ويشرف على إصـارها نخبة من أساتذة التربية وعلم النفس والعلوم الإنسانية بمصر والوطنه دورنه العربي.

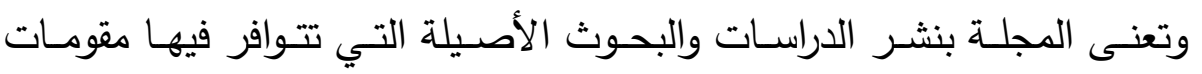

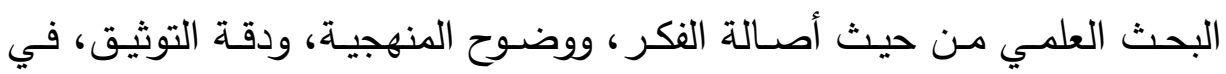

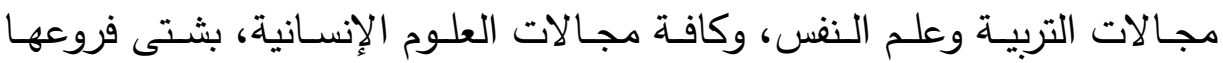

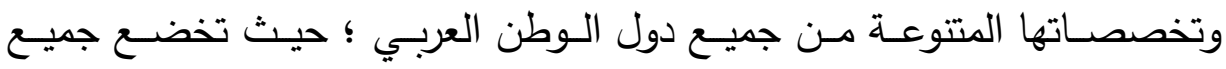

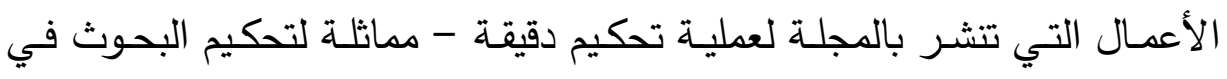

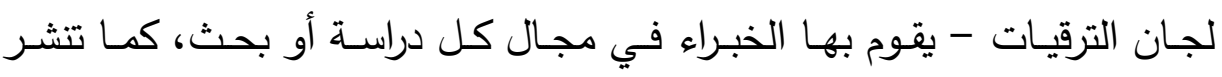
المجلـة تقارير المؤتمرات والندوات التربويـة، ومراجعات الكتب التربويـة والنفسية الحديثة، وملخصات الرسائل الجامعية في مجالات التربية المختلفة.

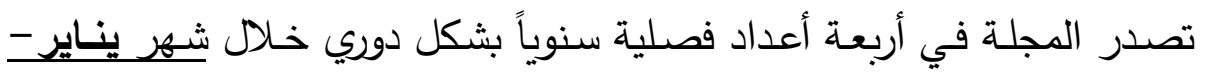

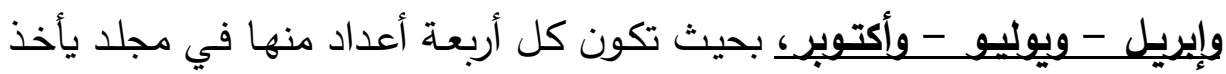

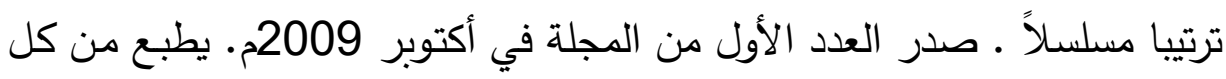

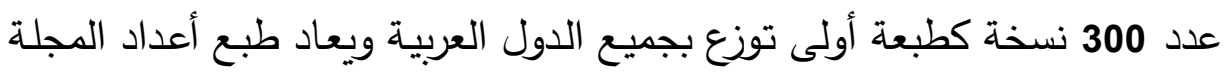

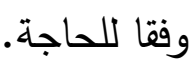

\section{قواعد النشر بالمجلة}

- تخضع البحوث والمقالات المقدمة للنشر للفحص وتحكيم أسـاتذة مرموقين في لي

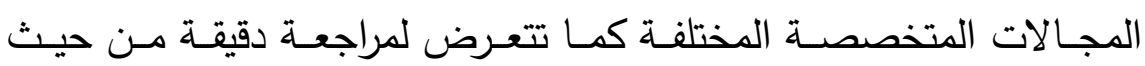

إتباعها لأصول كتابة التقارير العلمية.

-ويسر إدارة المجلة أن تعلن عن قواعد النشر بالمجلة التي سوف يتم تطبيقها

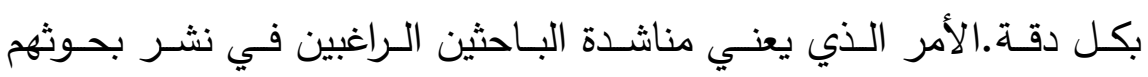

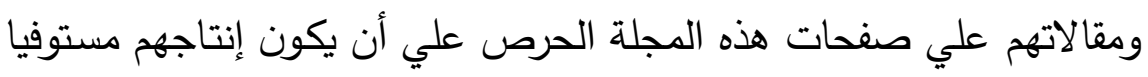


لهذه القواعد شكلا ومضمونا حتى يتجنب رفض البحث أو إعادته لإجراء تعديلات كثيرة . تعده

- أن يكون البحث أو المقال المطلوب نشرة بالمجلة جديد ولم يسبق نشرة في أي

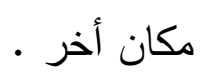

- تقدم الأبحاث مطبوعة علي الكمبيوتر علي مسافة مزدوجة بين الأسطر وهامش

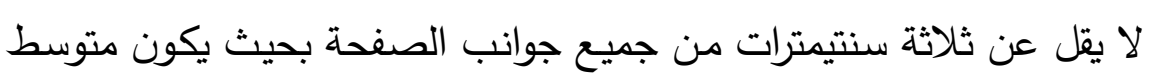

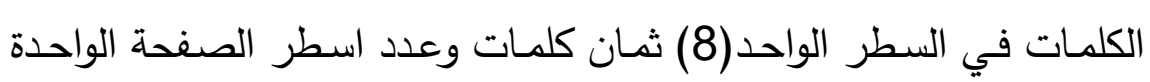

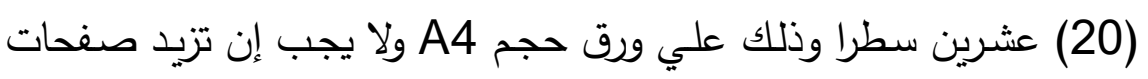

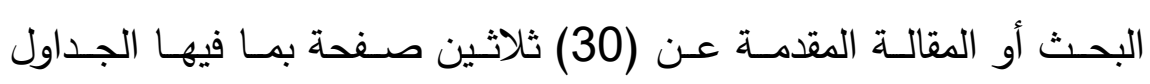
والأشكال والمراجع والملاحق.

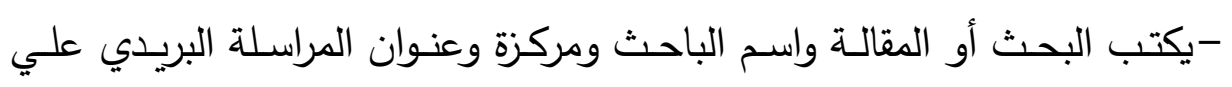
صفحة مستقلة في بداية البحث

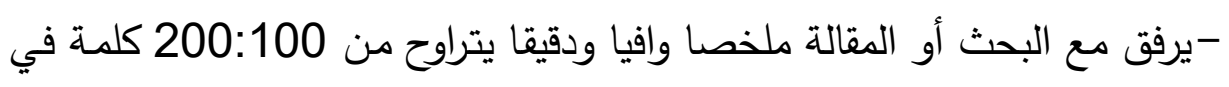
صفحة واحدة مستقلة. - تسـلم لإدارة المجلـة (3) ثـلاث نسـخ مـن البحـث لإغـراض المراجعـة والتحكيم

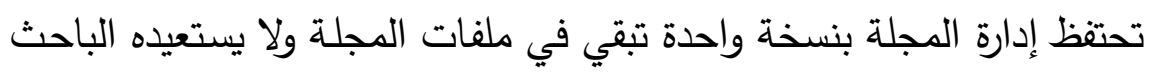

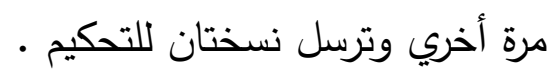

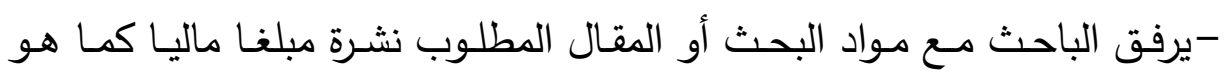

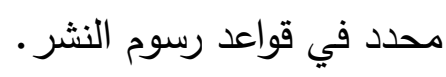

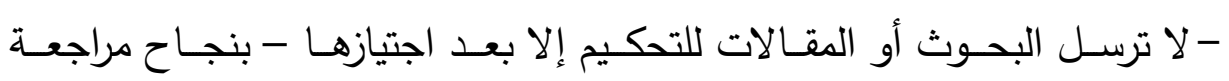

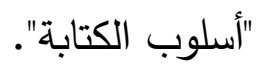

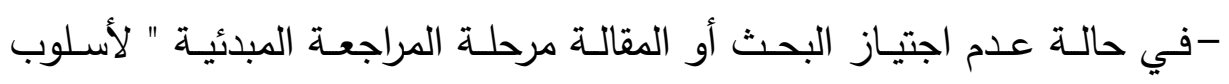

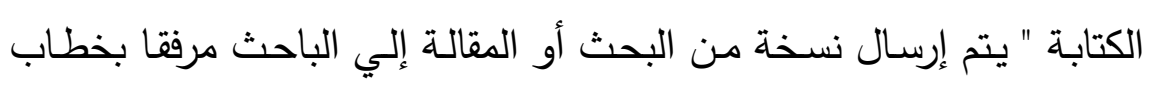

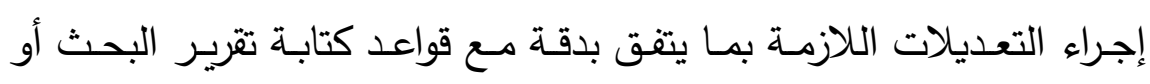


المقالـة التاليـة بالإضـافة إلي اتسـاقها مـع دليـل APA المـكور سـابقا مـع مطالبة الباحث بتسديد تكلفة البريد عن إعادة النسخة المعدلة للمجلة.

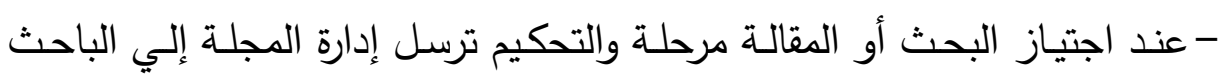

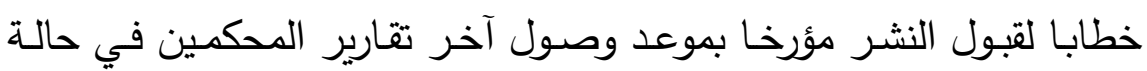
اجتياز البحث أو المقالة إلي الباحث مشفوعا بملاحظات هيئة التحكيم أمسا

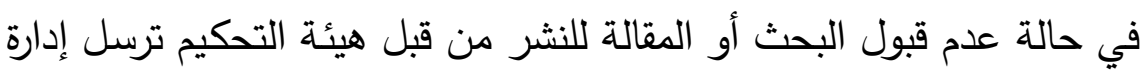
المجلة خطاب اعتذار عن نشر البحث أو المقال مرفقا بـه النسختين اللتين تعرضتا للتحكيم ولا يملك حق رفض أي بحث أو مقالة أو قبوله بعد إدخال

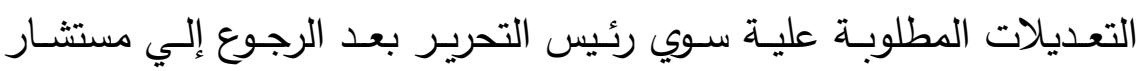
• التحرير

- بعد استيفاء الباحث للتعديلات المطلوبة ووصول البحث أو المقالة بعد التعديل إلي إدارة المجلة يدرج البحث أو المقالة في قائمة الانتظار الخاصـة بالمواد المقبولة للنشر تمهيدا لعملية الطباعة . -ومـع ظهور العـد الذي يضـم البحث أو المقالـة ترسـل المجلـة (5) مسـتلات Prints-Off

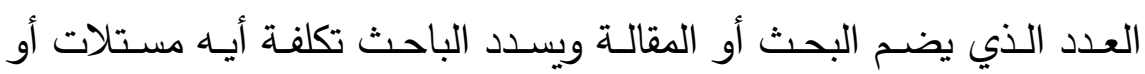

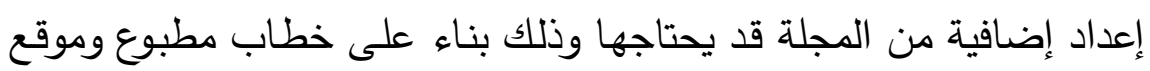
منه وموجه إلي إدارة المجلة

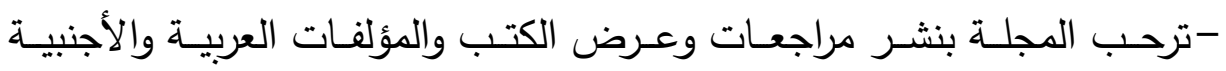
الصادرة خلال الأعوام الثلاثة السابقة علي صدور عدد المجلة المزمع نشرها

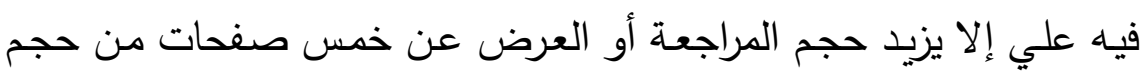

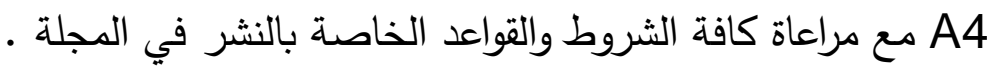
-كل ما ينشر في المجلة لا يجوز نشره بأي طريقة أو في أي مكان آخر دون

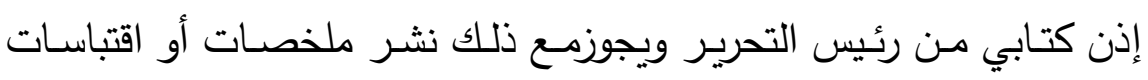


مختصرة بشرط الإشارة إلي المجلة باعتبارها المصدر الأصلي الذي ينبغي

$$
\text { الرجوع إليه. }
$$

- ترسل البحوث أو الدراسات باسم السيد الأستاذ الدكتور/ رئيس تحرير المجلة.

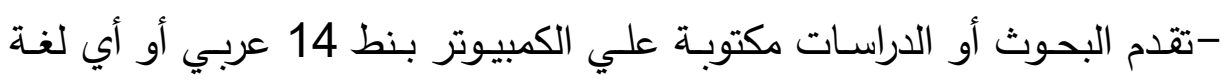

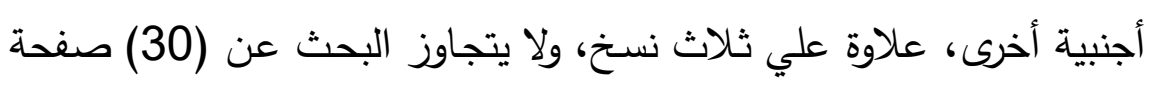

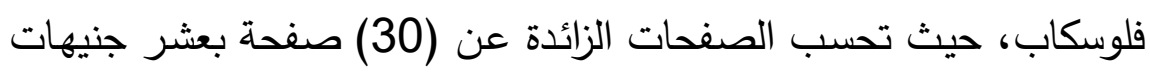
لكل صفحة للمصريين، وخمسة دولارات للباحثين في الخارج، ويرفق بالبحث الإسطوانة الممغنطة (C.D) مكتوب عليها البحث.

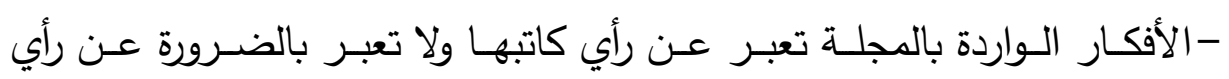

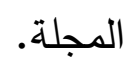

- ترتب البحوث أو الدراسات بالمجلة وفق اعتبارات تنظيمية خاصـة ولا علاقة لها بمكانه البحث والباحث. - لا تلتزم المجلـة بـرد البحـوث أو الدراسـات التي لا يتقـر نشـرها أو غير قابلـة •للنشر

\section{رسوم نشر الأبحاث}

رسوم النشر التي يتحملها أصحاب البحوث الراغبين في نشر بحوثهم في المجلة كالأتي :- مبلغ 1250 جنيها (500 هيئة تحكيم + 750 جنيـه للنشـر ) للبحث الذي الذي

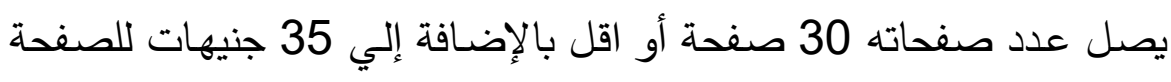
الواحدة التي يزيــ فيها البحث عـن 30 صـفحة وذلك للبـاحثين المصـريين أعضاء هيئة التدريس بالكلية أو خارجها

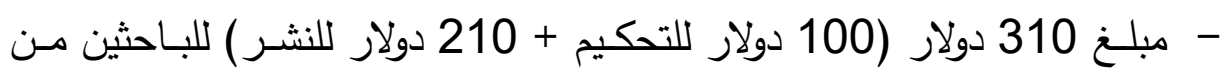

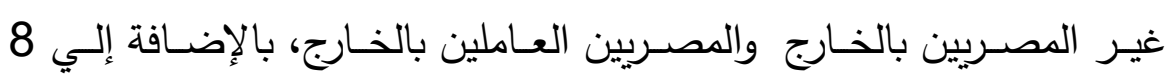

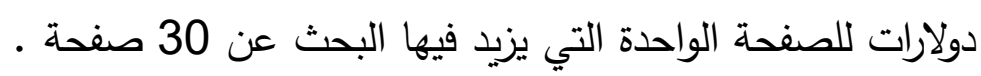


2020 - مجلة الدراسات التربوية والانسانية ـ كلية التربية ـ جامعة دمنهود ـ المجلد الثانى عشر - العدد الثالث

\section{قو اعد الاشتراك فى المجلة العلمية}

للراغبين في الحصول على المجلـة من داخل الجمهوريـة وخارجها طبقا للقرارات

$$
\text { والقواعد الآتية :- }
$$

- قيمة الاشتراك في المجلة العلمية داخل مصر 50 جنيهاً للنسخة الواحدة.

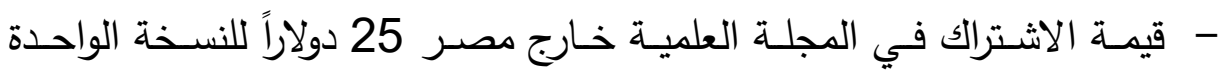
بخلاف تكاليف الثحن.

- علـي إن تسـد قيمـة الاشتراك بثـيك مقبـول الـدفع باسـم مجلـة كليـة التربيـة

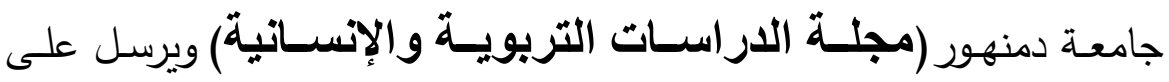

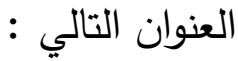

$$
\begin{aligned}
& \text { جمهورية مصر العربية - محافطة البحيرة }
\end{aligned}
$$

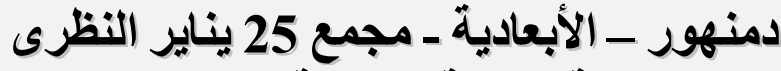

$$
\begin{aligned}
& \text { كلية التربية- جامعة دمنهور } \\
& \text { ت 002/045/3282225 - 002/045/3282222 } \\
& \text { فاكس 002/045/3282221 }
\end{aligned}
$$




\section{المحتـوبات}

\begin{tabular}{|c|c|c|}
\hline الصفحات & الموضوعات & 5 \\
\hline $66-19$ & فعالية برنامج تدربي قائم على التدريس المصغز باستخدام & 1 \\
\hline $134-67$ & 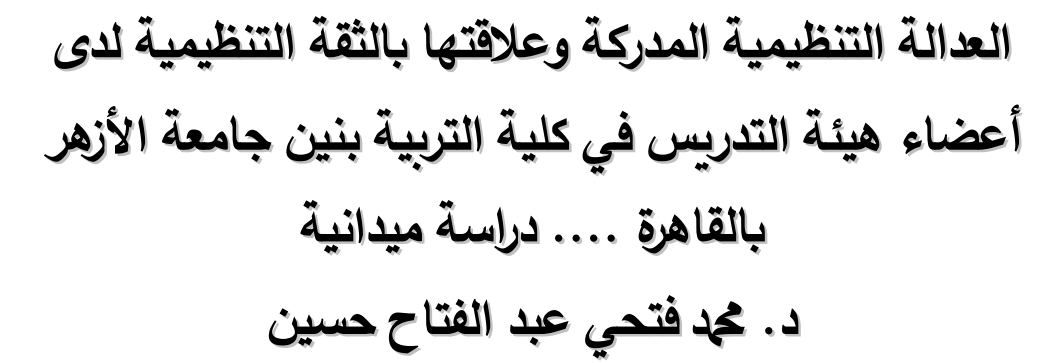 & 2 \\
\hline $178-135$ & العمالة الوافدة في دول الكوبت & 3 \\
\hline $216-179$ & 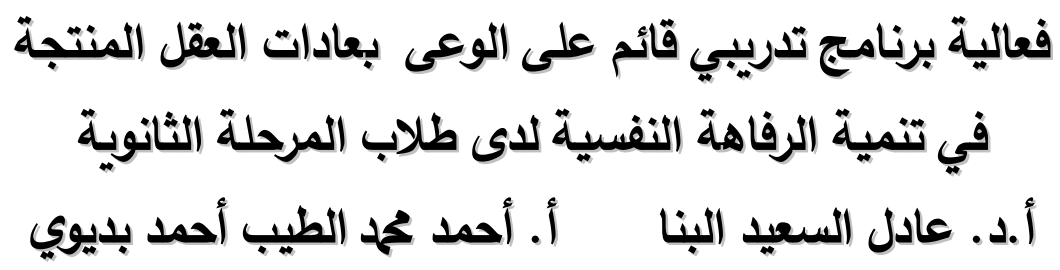 & 4 \\
\hline 286-217 & 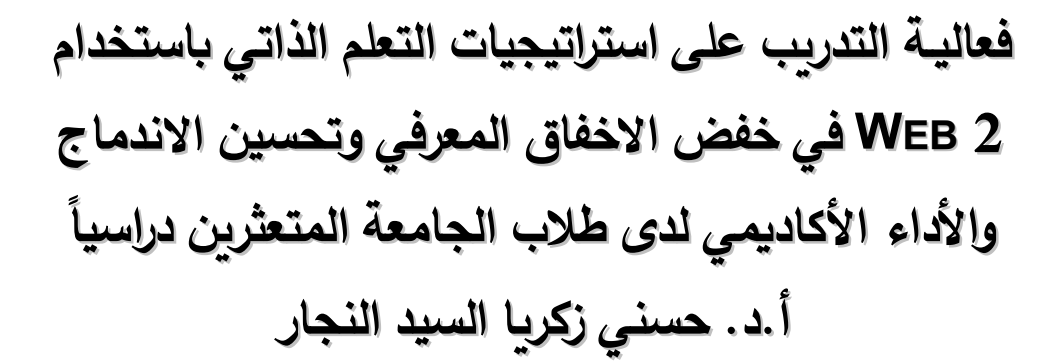 & 5 \\
\hline
\end{tabular}


2020 - مجلة الدراسات التربوية والانسانية . كلية التربية ـ جامعة دمنهود ـ المجلد الثانى عشر - العدد الثالث 